\title{
Oncologic PET/MRI, Part 2: Bone Tumors, Soft-Tissue Tumors, Melanoma, and Lymphoma
}

\author{
Christian Buchbender ${ }^{1}$, Till A. Heusner ${ }^{1}$, Thomas C. Lauenstein ${ }^{2}$, Andreas Bockisch ${ }^{3}$, and Gerald Antoch ${ }^{1}$ \\ ${ }^{I}$ Department of Diagnostic and Interventional Radiology, University of Dusseldorf, Dusseldorf, Germany; ${ }^{2}$ Department of Diagnostic \\ and Interventional Radiology and Neuroradiology, University of Duisburg-Essen, Essen, Germany; and ${ }^{3}$ Department of Nuclear \\ Medicine, University of Duisburg-Essen, Essen, Germany
}

\begin{abstract}
Learning Objectives: On successful completion of this activity, participants should be able to describe (1) the advantages and disadvantages of PET/MRI in oncologic applications in comparison to conventional imaging methods and PET/CT; (2) the limitations of PET/MRI compared with invasive staging procedures (biopsy); and (3) the metabolic-anatomic imaging procedure of choice (PET/MRI vs. PET/CT) based on tumor entity and location.

Financial Disclosure: The authors of this article have indicated no relevant relationships that could be perceived as a real or apparent conflict of interest.

CME Credit: SNM is accredited by the Accreditation Council for Continuing Medical Education (ACCME) to sponsor continuing education for physicians. SNM designates each JNM continuing education article for a maximum of 2.0 AMA PRA Category 1 Credit. Physicians should claim only credit commensurate with the extent of their participation in the activity.

For CE credit, participants can access this activity through the SNM Web site (http://www.snm.org/ce_online) through August 2013.
\end{abstract}

With integrated whole-body PET/MRI, a novel metabolicanatomic imaging technique recently has been introduced into clinical practice. This review addresses PET/MRI of bone tumors, soft-tissue sarcoma, melanoma, and lymphoma. If PET/ MRI literature is not yet available for some types of tumors, potential indications are based on available PET/CT and MRI data. PET/MRI seems to be of benefit in T-staging of primary bone tumors and soft-tissue sarcomas. With regard to $\mathrm{N}$-staging, $\mathrm{PET} / \mathrm{MRI}$ can be considered similarly accurate to PET/CT when applied as a whole-body staging approach. M-staging will benefit from MRI accuracy in the brain, the liver, and bone.

Key Words: MRI; PET; PET/MRI; oncology

J Nucl Med 2012; 53:1244-1252

DOI: 10.2967/jnumed.112.109306

I maging plays a key role in diagnosis and staging in oncology. Evaluation of local tumor extent and detection of potential locoregional lymph node or distant metastases according to the periodically revised standardized TNM cancer staging system (1) directly affects patient care by defining the most suitable therapy. With integrated wholebody PET/MRI, a new metabolic-anatomic imaging modality has been introduced into clinical practice. Despite the fact that the solution of basic problems, such as ade-

\footnotetext{
Received May 24, 2012; revision accepted Jun. 26, 2012.

For correspondence contact: Gerald Antoch, University of Dusseldorf, Medical Faculty, Department of Diagnostic and Interventional Radiology, Moorenstrasse 5, D-40225 Dusseldorf, Germany.

E-mail: antoch@med.uni-duesseldorf.de

Published online Jul. 10, 2012.

COPYRIGHT @ 2012 by the Society of Nuclear Medicine and Molecular Imaging, Inc.
}

quate MRI-based attenuation correction, is still a work in progress (2), reports on initial clinical experiences with PET/MRI in oncology are already available. In this second part of our review on PET/MRI in oncologic applications, we summarize the available first experiences with PET/ MRI in bone tumors, soft-tissue sarcoma, melanoma, and lymphoma. In fields where PET/MRI data are lacking, we outline the potential role of PET/MRI on the basis of the PET/CT and MRI literature. To provide further information on PET/MRI, we refer to our own unpublished experiences with PET/MRI in parts of this article. This contribution needs to be understood as supported solely by the authors' experience and should not be misinterpreted as evidencebased knowledge. In general, PET/MRI will be indicated and perform superiorly to PET/CT in those oncologic indications that require high soft-tissue contrast for diagnosis. Indications in which soft-tissue contrast is of limited importance will probably remain the domain of the workhorse, PET/CT (Table 1).

\section{TUMORS OF THE BONE}

\section{Primary Bone Tumors}

Initial Diagnosis and T-Staging. Aside from conventional radiography, MRI is the preferred imaging modality for the diagnosis and T-staging of malignant primary bone tumors (e.g., osteosarcomas) (3). An overlap of imaging findings between benign and malignant masses and the diagnosis of malignancy are typically aided by advanced MRI techniques. Nuclear MR spectroscopy, for example, has been shown to enhance the discrimination of benign from malignant tumors (4). The diagnostic accuracy reported for MRI in T-staging was $94 \%$ in a study retrospectively evaluating a heterogeneous cohort consisting of patients with bone and 
TABLE 1

Indications in Which PET/MRI Is Favorable to PET/CT, Depending on Tumor Entity

\begin{tabular}{|c|c|c|c|c|c|c|}
\hline \multirow[b]{2}{*}{ Tumor entity } & \multicolumn{4}{|c|}{$\begin{array}{l}\text { Most frequent site of } \\
\text { metastases }{ }^{*}\end{array}$} & \multirow{2}{*}{$\begin{array}{l}\mathrm{PET} / \mathrm{MRI} \text { is relevant for } \\
\text { (favorable to PET/CT)... } \\
\text { Staging category }\end{array}$} & \multirow[b]{2}{*}{ Special objective/prognostic factor } \\
\hline & Brain & Lung & Liver & Bone & & \\
\hline Soft-tissue sarcoma & - & + & + & - & $\mathrm{T} / \mathrm{M}$ & $\begin{array}{l}\text { Tumor size and depth of infiltration } \\
\text { defines T category; muscular, neurovascular, } \\
\text { and bone invasion }\end{array}$ \\
\hline Primary bone tumors & - & + & - & - & $\mathrm{T}$ & $\begin{array}{l}\text { Presurgical evaluation (e.g., neurovascular } \\
\text { invasion); exact tumor size and response to } \\
\text { neoadjuvant treatment }\end{array}$ \\
\hline Melanoma & + & + & + & + & $\mathrm{M}$ & $\begin{array}{l}\text { Exact number and location of metastases } \\
\text { for presurgical evaluation }\end{array}$ \\
\hline Lymphoma & & & & & $\mathrm{M}$ & $\begin{array}{l}\text { Extranodal dissemination; early therapy } \\
\text { response assessment }\end{array}$ \\
\hline
\end{tabular}

${ }^{*}$ Frequency of metastatic spread (frequently [+], rare [-]) is according to AJCC Cancer Staging Manual, seventh edition (1); PET/CT and $\mathrm{PET} / \mathrm{MRI}$ are considered equally accurate for $\mathrm{N}$-staging, and thus importance of $\mathrm{N}$-staging is not discussed.

soft-tissue sarcoma (5). In the same study, the combined metabolic-anatomic approach using ${ }^{18} \mathrm{~F}$-FDG PET/CT for T-staging, with $96 \%$ accuracy, was reported to exceed even the excellent performance of MRI, a result that may be considered rather unexpected in view of the inferior softtissue contrast of CT to that of MRI and the well-known limitations of ${ }^{18} \mathrm{~F}$-FDG PET for $\mathrm{T}$-staging of various tumors. However, data on integrated PET/MRI for T-staging of malignant primary bone tumors are not yet available. We believe that PET/MRI may not increase the diagnostic accuracy of T-staging of bone tumors over MRI alone, but a whole-body PET/MRI approach may offer TNM staging with high accuracy in a single session. T-staging will benefit from the MRI data, N-staging will benefit from PET, and M-staging will benefit from the combination. The PET component of PET/MRI will be able to guide diagnostic biopsies and help maximize the accuracy of correct staging and grading, with a consequent impact on treatment and outcome (3).

$N$-Staging. Another advantage of integrated PET/MRI in malignant primary bone tumors is that accurate local staging with high resolution can be paired with a sensitive metabolic whole-body staging examination. In a retrospective study on 117 patients, ${ }^{18} \mathrm{~F}$-FDG PET/CT had a sensitivity, specificity, positive predictive value (PPV), negative predictive value (NPV), and accuracy of $88 \%, 97 \%, 82 \%$, $98 \%$, and $96 \%$, respectively, and was significantly more accurate for $\mathrm{N}$-staging in malignant bone tumors than conventional staging examinations (MRI of the tumor location and whole-body CT) (5). Analogously, PET/MRI is expected to be of similar accuracy to PET/CT for the detection of lymph node metastases from malignant bone tumors. Direct comparison to conventional morphologic imaging reveals that ${ }^{18} \mathrm{~F}$-FDG PET foremost contributes to the sensitivity of lymph node metastasis detection (53\% vs. $72 \%)$ at a high level of specificity (5).
Restaging and Response to Therapy. Patients with relapsing malignant bone tumors have a poor prognosis (3). Although there is no guideline-established role for metabolic imaging in restaging of bone tumors, some promising results on the diagnostic value of ${ }^{18} \mathrm{~F}-\mathrm{FDG}$ PET/CT can be found in the literature. ${ }^{18} \mathrm{~F}$-FDG PET/CT has high accuracy in restaging, with a sensitivity, specificity, and accuracy of $87 \%, 97 \%$, and $94 \%$, respectively (6). In a prospective comparative study assessing therapy response in pediatric osteosarcomas, ${ }^{18} \mathrm{~F}-\mathrm{FDG}$ PET was able to discriminate responders from nonresponders, but CT and MRI (measurements of the tumor volume) were not (7). Interestingly, a subgroup analysis of the same study revealed that ${ }^{18} \mathrm{~F}-\mathrm{FDG}$ PET was not beneficial for therapy response evaluation in Ewing sarcoma-type tumors. MRI techniques that go beyond tumor size and volume, such as dynamic contrast-enhanced MRI and diffusion-weighted MRI, have proven sensitive to chemotherapy-induced tumor necrosis and thus can also be used to evaluate therapy response (8). However, both MRI and ${ }^{18}$ F-FDG PET are of value for restaging and response assessment in primary bone tumors. The integration of these components by PET/MRI offers a whole new field for research on this topic.

\section{Bone Metastases}

Approximately $50 \%$ of cancer patients are estimated to experience severe bone pain. Frequently, especially in prostate, breast, and lung cancer, metastases are found to be causal (9). Imaging plays a pivotal role in the diagnosis of a metastatic osseous spread, and morphologic (CT and MRI) and functional (scintigraphy and PET) imaging modalities are routinely applied in cancer patients. A metaanalysis comparing the diagnostic performance of radiologic and nuclear medicine methods, and their combination, for bone metastasis detection in more than 15,000 patients 
provided the broadest data so far (10). ${ }^{18} \mathrm{~F}-\mathrm{FDG}$ PET, with a sensitivity of $90 \%$ and specificity of $97 \%$, was as accurate as MRI, at $91 \%$ and $95 \%$, respectively. When integrated ${ }^{18}$ F-FDG PET/CT was applied, sensitivity increased to $94 \%$, and the same high specificity of $97 \%$ was preserved (10). A subanalysis revealed a higher sensitivity (95\%) alongside a lower specificity $(89 \%)$ when studies that included diffusion-weighted MRI sequences were compared with studies that did not ( $88 \%$ and $97 \%$, respectively). ${ }^{18} \mathrm{~F}$ FDG PET, ${ }^{18}$ F-FDG PET/CT, and MRI were significantly more accurate for bone metastasis detection than were bone scintigraphy and stand-alone CT (10). A smaller but prospectively designed comparative study reported a higher overall accuracy for whole-body MRI $(91 \%)$ than for ${ }^{18} \mathrm{~F}$ FDG PET/CT (78\%). Whole-body MRI, according to that study, was clearly superior to ${ }^{18}$ F-FDG PET/CT in sensitivity. Sensitivity was $94 \%$ for MRI and $78 \%$ for ${ }^{18} \mathrm{~F}-\mathrm{FDG}$ PET/CT, with comparable specificities $(76 \%$ and $80 \%$, respectively) (11). One reason for the significantly better performance of MRI in that study may have been a larger number of patients with diffuse (but small-volume) osseous metastases, which may be missed on ${ }^{18}$ F-FDG PET and on CT. The smallest detectable bone metastasis was $2 \mathrm{~mm}$ on MRI, compared with $5 \mathrm{~mm}$ on ${ }^{18} \mathrm{~F}-\mathrm{FDG}$ PET/CT (11). The results of these studies are well suited to giving a general impression on the diagnostic performance of different imaging methods. On the other hand, reliable data on diagnostic accuracy in certain cancer types are of higher practical relevance. For example, whole-body MRI was less sensitive (77\% vs. $92 \%)$ and specific $(92 \%$ vs. $98 \%)$ than ${ }^{18}$ F-FDG PET $/{ }^{18}$ F-FDG PET/CT for the detection of bone metastases, as well as being less sensitive (77\% vs. $86 \%$ ) but more specific ( $92 \%$ vs. $88 \%$ ) than bone scintigraphy in lung cancer patients (12). In contrast, MRI was more sensitive than ${ }^{18} \mathrm{~F}$-FDG PET and bone scintigraphy (97\% vs. $83 \%$ vs. $87 \%$ ) for the detection of bone metastases in breast cancer patients (13). These findings indicate that for a reasonable judgment on the favored imaging modality in a cer- tain cancer entity, differentiated studies are indispensible. Both PET/CT and MRI suffer from false-negative results requiring periodic restaging (14).

The presented data outline the high capability of ${ }^{18} \mathrm{~F}$ FDG PET for assessing the skeletal system for metastases and the additional value of integrated PET in combination with a coregistered morphologic reference, that is, ${ }^{18} \mathrm{~F}-\mathrm{FDG}$ PET/CT. Metabolic imaging with PET is clearly advantageous over bone scintigraphy and stand-alone CT. MRI, especially when incorporating diffusion-weighted sequences, seems to have an at least comparable accuracy to ${ }^{18} \mathrm{~F}$ FDG PET/CT. MRI can depict metastatic bone marrow invasion before the development of structural damage visible on CT or of responsive osteoblastic activity visible on bone scintigraphy (15). Moreover, diffusion-weighted MRI is of use in assessing the response of bone metastases to systemic therapy, as has been shown for osseous prostate cancer metastases treated with antiandrogens (16). For integrated skeletal imaging in combination with PET, MRI is, therefore, more promising than CT. PET/MRI will enhance the detection of bone metastases and is strongly awaited as an imaging method that will exceed the performance of PET/CT (Fig. 1).

\section{SOFT-TISSUE SARCOMA}

Initial Diagnosis and T-Staging. In cases of an undetermined soft-tissue mass, MRI with its high soft-tissue contrast and lack of radiation exposure is often the first choice in cross-sectional imaging (17), especially in children. In this setting, differentiation of malignant from benign masses is of utmost importance. Reports of up to $90 \%$ accuracy for MRI in discriminating benign from malignant lesions (18) are hampered by the results of other MRI studies revealing that a correct classification in accordance with histopathology can be reached in only $25 \%-33 \%$ of cases (19). Reports are emerging on the utility of advanced MRI techniques, such as nuclear MR spectroscopy, that could potentially contribute to differentiation between malignant
FIGURE 1. A 55-y-old patient with metastatic breast carcinoma. Unremarkable sclerotic lesion (arrow) of left femoral bone on axial CT (A) was diagnosed as metastasis only because it was strongly ${ }^{18} \mathrm{~F}-\mathrm{FDG}$-avid on PET/CT (B). Whole-body MRI using T1weighted fat-suppressed sequence (C) clearly depicts metastasis as contrastenhancing mass (arrowhead). Corresponding PET/MR image (D) demonstrates precise metabolic-anatomic correlation of this technique for bone imaging.
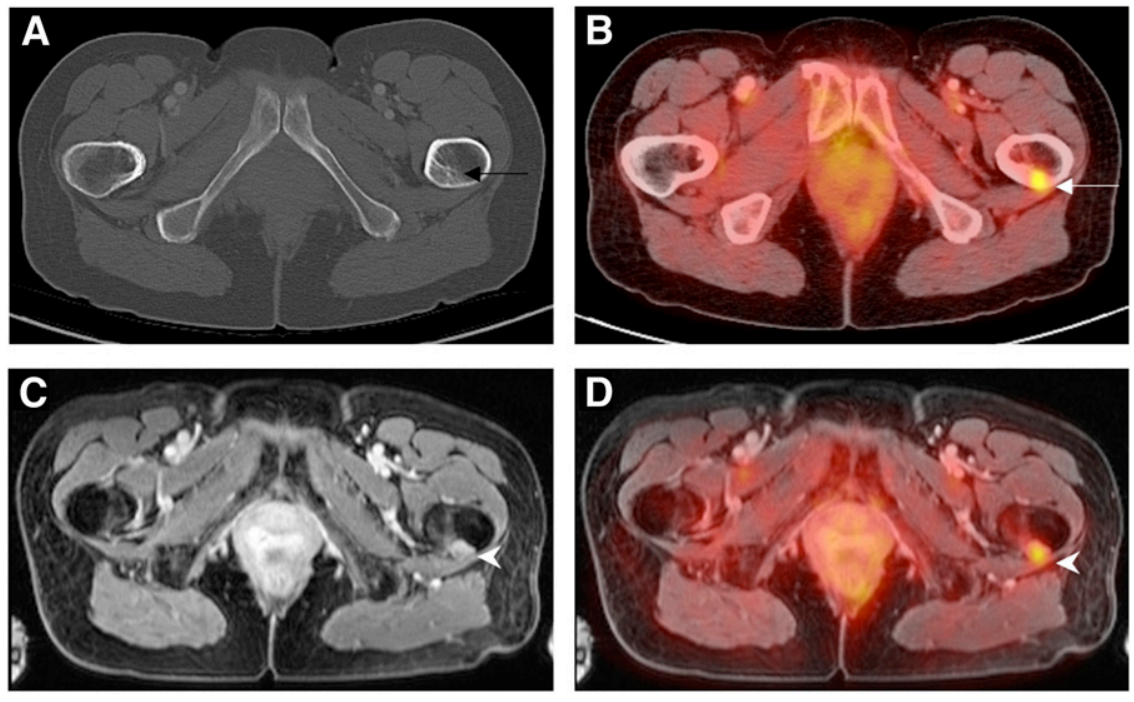
and benign soft-tissue masses (20), but for a conclusive and secure diagnosis, patients with indecisive MRI or CT findings will undergo biopsy in most cases (17). The availability of additional PET data will not obviate definite histopathologic diagnosis by biopsy; thus, PET/MRI is not expected to be of additional use in the primary diagnosis of undetermined softtissue masses. But analogously to ${ }^{18} \mathrm{~F}-\mathrm{FDG}$ PET, there might be an indication for integrated whole-body PET/MRI in the diagnostic algorithm in cases of sarcoma in which the primary location is unknown (21).

Based on its high soft-tissue contrast, MRI is the modality of choice for assessing local tumor infiltration (22). ${ }^{18}$ F-FDG PET does not add information to MRI for Tstaging in soft-tissue sarcomas (23). On the other hand, ${ }^{18} \mathrm{~F}$ FDG PET provides additional prognostic information. Higher metabolic activity (maximum standardized uptake value) of the primary tumor has recently been shown to predict shorter survival in a retrospective evaluation of 41 children with rhabdomyosarcoma (24). Planning of surgical tumor excisions is often based on the depth of infiltration found on MRI. ${ }^{18}$ F-FDG PET can determine a safe tumorfree surgical margin by applying a threshold of less than 1 for maximum standardized uptake value (25). PET/MRI may thus be used to guide the surgeon in preoperative planning of tumor resection. Our own initial experience with PET/MRI in patients with soft-tissue sarcoma indicates that integrated PET/MRI can replace stand-alone morphologic imaging, with a focus of the ${ }^{18} \mathrm{~F}-\mathrm{FDG}$ PET component for prognostic questions and assessment of $\mathrm{N}$ stage and M-stage (Fig. 2).

$N$-Staging. On the basis of experience with ${ }^{18} \mathrm{~F}$-FDG PET versus conventional morphologic imaging, PET/MRI is promising for $\mathrm{N}$-staging of patients with soft-tissue sarcoma. A recent prospective comparative study on soft-tissue sarcoma staging reported that ${ }^{18} \mathrm{~F}$-FDG PET is superior to conventional diagnostic imaging techniques (MRI of the tumor primary site, whole-body CT, and ${ }^{99 \mathrm{~m}} \mathrm{Tc}-\mathrm{methyl}$ diphosphonate bone scintigraphy) for $\mathrm{N}$-staging, with a sensitivity of $95 \%$ versus $25 \%$, respectively $(26) .{ }^{18} \mathrm{~F}-\mathrm{FDG}$ $\mathrm{PET} / \mathrm{CT}$ was reported to change the N-stage in 4 of 13 rhabdomyosarcoma patients in a smaller series (21). Interestingly, a retrospective study on PET with the radiotracer ${ }^{11} \mathrm{C}$-choline reported $100 \%$ accuracy for $\mathrm{N}$-staging in softtissue sarcomas and an overall accuracy of $94 \%$ for TNM staging, versus $50 \%$ for conventional imaging modalities (27). The presence of highly metabolically active lymph node metastases is predictive of a shorter survival, and thus ${ }^{18} \mathrm{~F}$-FDG PET for $\mathrm{N}$-staging provides relevant prognostic information (24). The indication for PET/MRI will thus include combined T-, N-, and M-staging in a single session.

Restaging and Response to Therapy. MRI, whole-body $\mathrm{CT}$, and bone scintigraphy or a combination of these methods is applied for restaging of patients with soft-tissue sarcoma. A metaanalysis on the diagnostic performance of ${ }^{18}$ F-FDG PET/CT reported $100 \%$ sensitivity, 96\% specificity, 99\% PPV, 100\% NPV, and 99\% overall accuracy for restaging sarcoma patients (28). In the same analysis, ${ }^{18} \mathrm{~F}$ FDG PET was more accurate than stand-alone CT. Comparative studies have proven that a side-by-side reading of ${ }^{18}$ F-FDG PET and conventional imaging techniques leads to a significantly higher number of correct therapeutic decisions than does conventional imaging alone (91\% vs. 59\%) (26). There is evidence that the simple evaluation of tumor size is inadequate for assessing the response of soft-tissue
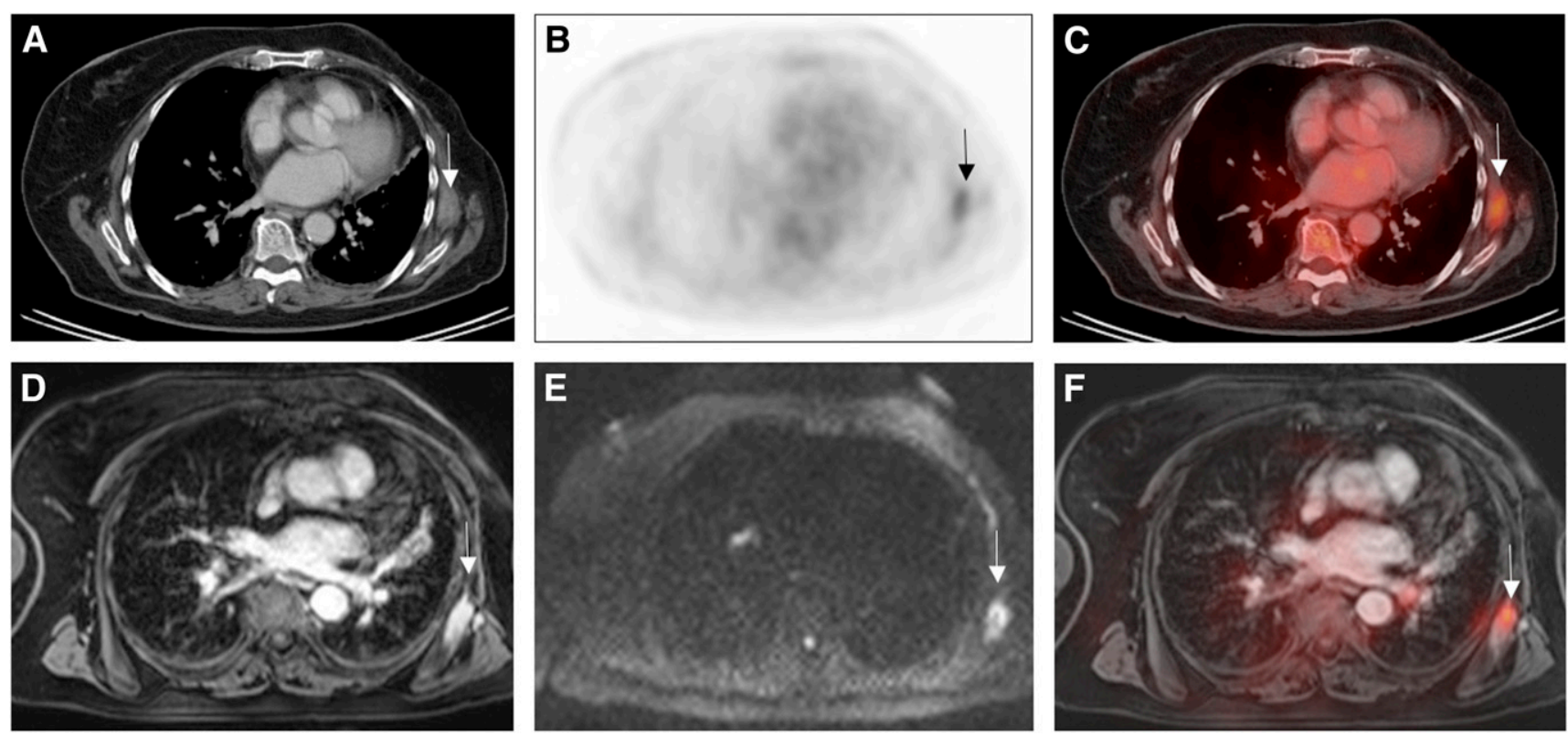

FIGURE 2. A 63-y-old patient with sarcoma metastasis in left anterior serratus muscle. Axial contrast-enhanced CT (A) shows ill-defined muscle-isodense soft-tissue mass (arrow) that is ${ }^{18} \mathrm{~F}-\mathrm{FDG}$-avid on ${ }^{18} \mathrm{~F}-\mathrm{FDG}$ PET (B) and ${ }^{18} \mathrm{~F}-\mathrm{FDG}$ PET/CT (C). Extent of this mass is better depicted on axial contrast-enhanced fat-suppressed MRI (D). Diffusion-weighted MR image (E) depicts this metastasis as high-signal diffusion-restricted lesion (arrow) and demonstrates sensitivity of diffusion-weighted MRI. ${ }^{18} \mathrm{~F}-\mathrm{FDG}$ PET/MR image is also shown (F). 
sarcomas to therapy (29), and thus markers of tumor biology and metabolism are of increasing importance. Conventional MRI, as well as functional MRI, provides a whole bouquet of information on tumor size, perfusion, tissue composition, and extent of tumor necrosis and plays an important role in assessing the response of soft-tissue sarcomas (30). Diffusion-weighted MRI, for example, has been shown to provide a measure of tumor cellularity, with a reverse linear relation between measured adenylate cyclase values and cellular count in soft-tissue sarcoma histopathology (31). Moreover, a strong correlation between a change in tumor adenylate cyclase and a change in tumor volume under chemotherapy has been demonstrated (32). Diffusion-weighted MRI thus provides a valuable tool for the assessment of cytotoxic therapy response. Metabolic imaging with ${ }^{18} \mathrm{~F}$-FDG PET is also sensitive for assessing the therapeutic response of patients with soft-tissue sarcoma. In a prospective study, the reduction of metabolic activity between 2 consecutive ${ }^{18}$ F-FDG PET examinations during chemotherapy correctly predicted pathologic tumor response in $95 \%$ of patients $(n=42)$ and was more accurate for this prediction than was a reduction of tumor size (33). With a threshold of a $60 \%$ decrease in maximum standardized uptake value, ${ }^{18}$ F-FDG PET had $100 \%$ sensitivity and $71 \%$ specificity for the prediction of pathologic tumor response (33). A different study, applying a threshold of a $35 \%$ decrease in maximum standardized uptake value under chemotherapy, discriminated therapy responders from nonresponders with $100 \%$ sensitivity and $67 \%$ specificity as early as after the first chemotherapy cycle (34). Despite these promising reports, recent emerging evidence has questioned the value of ${ }^{18} \mathrm{~F}$-FDG PET for the evaluation of neoadjuvant therapy in soft-tissue sarcoma (35), indicating that there still is research to be done on this topic. Follow-up data on the diagnostic performance of integrated PET/MRI are currently not available. The simultaneous acquisition of dynamic functional MRI and PET information-for example, simultaneous contrast-enhanced dynamic MRI and dynamic PET_-offers a new quality of bioinformation in soft-tissue sarcoma restaging and therapy response assessment.

\section{MELANOMA}

Initial Diagnosis and T-Staging. Diagnosis of malignant melanoma of the skin is based on clinical inspection and full-thickness biopsy, and tumor stage according to the American Joint Committee on Cancer (AJCC) classification is based on the presence of ulceration and tumor thickness as confirmed by histopathology (36). Generally, CT, MRI, and ${ }^{18}$ F-FDG PET depict melanomas with variable sensitivity and specificity depending on size and location. However, there is no current indication for imaging in the primary diagnosis and T-staging of malignant melanomas.

$\mathrm{N}$-Staging. The risk for locoregional metastases is stratified according to the depth of tumor infiltration (AJCC classification). According to current guidelines, in mela- noma patients with a tumor thicker than $1 \mathrm{~mm}$, sentinel lymph biopsy should be considered, followed by locoregional lymphadenectomy in cases of positivity for metastatic disease (37). This algorithm is based on the weak performance of imaging modalities for $\mathrm{N}$-staging in malignant melanoma when small metastases and micrometastases are considered. A metaanalysis on the diagnostic performance of different imaging modalities for $\mathrm{N}$-staging in melanoma patients reported a sensitivity and specificity of $60 \%$ and $97 \%$ for ultrasonography, which was the highest accuracy achieved in comparison with the low values for CT (9\% and 92\%, respectively), ${ }^{18} \mathrm{~F}-\mathrm{FDG}$ PET (30\% and 96\%, respectively), and ${ }^{18}$ F-FDG PET/CT (11\% and 97\%, respectively) (38). The prospectively evaluated sensitivity, specificity, PPV, and NPV of sentinel lymph node biopsy for detection of occult locoregional lymph node metastases was $94 \%, 100 \%, 100 \%$, and 99\%, respectively (39). The explanation for the low sensitivity of imaging studies can potentially be found in the small mean tumor volume of lymph node metastases $\left(<5 \mathrm{~mm}^{3}\right)$ that is regularly found in melanoma patients $(39,40)$. These small nests of tumor cells are frequently missed on morphologic and metabolic scans. However, in patients with positive results on sentinel lymph node biopsy, imaging is required and recommended to exclude further metastatic spread (37). In a prospective study on ${ }^{18}$ F-FDG PET in AJCC stage III patients with positive sentinel lymph node biopsy and with CT, MRI, and ultrasonography negative for disseminated disease, ${ }^{18} \mathrm{~F}-\mathrm{FDG}$ PET revealed unknown distant metastases and thus upstaged $4(12 \%)$ of 33 patients to AJCC stage IV (41). Whole-body MRI, with a sensitivity, specificity, PPV, NPV, and accuracy of $66 \%, 77 \%, 84 \%, 55 \%$, and $67 \%$, respectively, for the detection of lymph node metastases, has been shown to be equal in accuracy to whole-body CT (42) and inferior to ${ }^{18} \mathrm{~F}-\mathrm{FDG}$ PET/CT (43). Another comparative study on the same topic found whole-body MRI to be at least as accurate as ${ }^{18} \mathrm{~F}$-FDG PET/CT for $\mathrm{N}$-staging, using a combination of conventional MRI sequences and diffusionweighted MRI (44). The rather sobering performance of whole-body MRI for $\mathrm{N}$-staging in malignant melanoma has to be seen in the context of major advantages that whole-body MRI provides in the detection of subcutaneous, bone, liver, and brain metastases. Integrated PET/MRI will, therefore, be a tool to achieve whole-body melanoma staging in a single session (Fig. 3).

Restaging and Response to Therapy. The risk of tumor recurrence in malignant melanoma depends on the primarytumor thickness. In low-risk patients (tumor thickness $<1 \mathrm{~mm}$, AJCC stages $0-\mathrm{Ib}$ ), surveillance relies solely on clinical follow-up and routine self-examinations of the skin and lymph nodes (37). Restaging with ultrasound, CT, MRI, and PET/CT according to current guidelines (37) is reserved to, but not mandatory in, high-risk patients. A retrospective study in high-risk melanoma patients found that ${ }^{18} \mathrm{~F}-\mathrm{FDG}$ PET/CT, with a sensitivity, specificity, NPV, and PPV of 97\%, was more accurate for the detection of tumor 

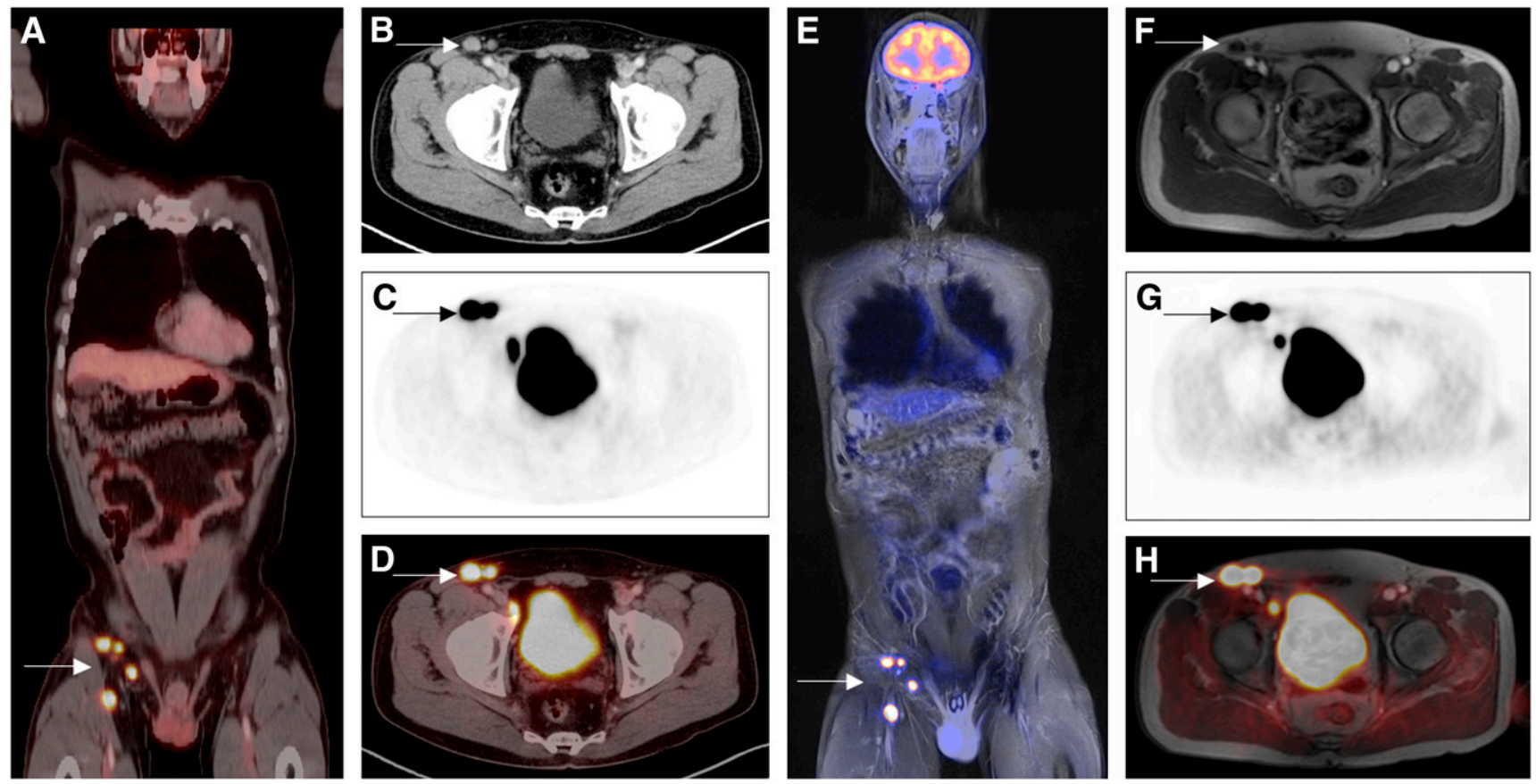

FIGURE 3. A 65 -y-old patient with pathologically confirmed T4b malignant melanoma of right leg. Coronal whole-body ${ }^{18} \mathrm{~F}-\mathrm{FDG}$ PET/CT (A), axial contrast-enhanced CT (B), axial ${ }^{18} \mathrm{~F}-\mathrm{FDG}$ PET (C), and axial ${ }^{18} \mathrm{~F}-\mathrm{FDG}$ PET/CT (D) show multiple enlarged and ${ }^{18} \mathrm{~F}-\mathrm{FDG}-\mathrm{avid}$ inguinal and iliac lymph node metastases (arrows). Coronal ${ }^{18} \mathrm{~F}-\mathrm{FDG}$ PET/MRI (E), axial T1-weighted MRI (F), axial ${ }^{18} \mathrm{~F}-\mathrm{FDG}$ PET performed simultaneously with $\mathrm{MRI},(\mathrm{G})$ and axial ${ }^{18} \mathrm{~F}-\mathrm{FDG}$ PET/MRI $(\mathrm{H})$ are as accurate as PET/CT for visualization of lymph node metastases.

recurrence than the tumor marker S100 (respective values: $86 \%, 45 \%, 61 \%$, and $76 \%$ ) (45). The same study revealed that PET/CT, compared with S100, had a significantly higher prognostic value for cancer-related mortality. In a different study, S100 positivity was used as a pretest for tumor recurrence detection in asymptomatic high-risk melanoma patients, with a sensitivity of $100 \%$, a specificity of $90 \%$, a PPV of $96 \%$, and an NPV of $100 \%$ (46). According to the results of a recent metaanalysis, the PPV of PET/CT for the detection of recurrent metastases is stage-dependent, yielding a higher PPV in high-risk patients $(80 \%)$ than in intermediate-risk patients $(63 \%)$ and low-risk patients (33\%) (38). Besides the reliable detection, a precise localization of relapsing disease is crucial for therapeutic, that is, surgical, decisions. A prospective study on the impact of imaging on surgical decision making in melanoma patients reported that in $25 \%-75 \%$ of patients, surgery was adapted on the basis of findings on ${ }^{18} \mathrm{~F}$-FDG PET/CT (47). MRI has also been shown to influence the therapeutic approach in melanoma patients. Therapy was changed in $64 \%$ of patients $(n=41)$ and included adaption of the surgical approach in 10 patients after reevaluation of disease spread on wholebody MRI, including diffusion-weighted imaging (43). Moreover MRI, with its higher soft-tissue contrast, has proven to be clearly superior for the detection of metastases in important organ sites, with an impact on therapy strategies for, for example, liver and brain (42-44). Both ${ }^{18} \mathrm{~F}$-FDG PET/CT and MRI are sensitive to changes under local and systemic therapy. ${ }^{18} \mathrm{~F}-\mathrm{FDG}$ PET/CT has been shown to outperform the tumor marker S100 in the discrimination of responders from nonresponders in a study on stage IV melanoma patients (48). Responders to chemotherapy identified by ${ }^{18} \mathrm{~F}-\mathrm{FDG}$ PET/CT in a retrospectively performed evaluation have been proven to have a longer progression-free and overall survival than nonresponders (48). Experimental studies performed mainly ex vivo on melanoma xenografts reported that the amount of tumor cell necrosis and the oxygenation status of tumor cells could be assessed using nuclear MR spectroscopy (49). More clinically relevant is the potential of MRI in restaging brain metastases, as these have been proven to be predictive of a poor prognosis (48). Data on the performance of integrated PET/MRI in melanoma restaging and response assessment are awaited but not available at present. We expect clinical PET/MRI to become a 1-stop-shop whole-body $\mathrm{N}$ - and $\mathrm{M}$-staging tool in high-risk patients (AJCC stages > III) (Fig. 3).

\section{LYMPHOMA}

Initial Diagnosis and Staging. In both Hodgkin disease and non-Hodgkin lymphoma, imaging plays an important role for primary diagnosis and staging, with an impact on therapy (50). Current guidelines encourage the use of ${ }^{18} \mathrm{~F}-$ FDG PET/CT for primary staging of ${ }^{18} \mathrm{~F}-\mathrm{FDG}$-avid and potentially curable lymphomas (e.g., diffuse large B-cell lymphoma, Hodgkin disease), particularly with regard to the 2007 revised response criteria $(51,52)$ that include the evaluation of tumor tissue metabolism (53). The performance of ${ }^{18} \mathrm{~F}$-FDG PET in lymphoma has been assessed 
extensively in the literature. In a retrospective analysis, ${ }^{18}$ F-FDG PET/CT, with an accuracy of $94 \%$, was more accurate than conventional staging procedures $(89 \%)$, including CT and bone marrow biopsy (54). Some authors argue that ${ }^{18} \mathrm{~F}-\mathrm{FDG}$ PET/CT might even eliminate the need for bone marrow biopsy in the primary staging of Hodgkin disease because ${ }^{18}$ F-FDG PET/CT is highly sensitive and specific for bone marrow involvement in this disease, at $92 \%$ and $90 \%$, respectively (55). Except for cerebral lymphoma, whole-body MRI is currently of high research interest but minor importance in the staging algorithm of lymphoma patients. This situation soon might substantially change, and whole-body MRI might become a good alternative to CT (56). There is evidence that whole-body diffusion-weighted MRI, with a sensitivity of $90 \%$ and a specificity of $94 \%$, could be as accurate as ${ }^{18}$ F-FDG PET/CT for the staging of Hodgkin disease and non-Hodgkin lymphoma $(57,58)$. Interestingly, particularly in small, indolent lymphomas that are not considerably ${ }^{18}$ F-FDG-avid, additional information might be gained from diffusion-weighted MRI (59). MRI, in a recent metaanalysis, was almost equally sensitive $(90 \%)$ to ${ }^{18} \mathrm{~F}$ FDG PET/CT for the detection of bone marrow involvement in Hodgkin disease but was less specific (75\%) (55). The addition of diffusion-weighted MRI significantly increased the accuracy of whole-body MRI for primary staging of lymphoma patients, leading to $94 \%$ concordance with the findings on ${ }^{18} \mathrm{~F}-\mathrm{FDG}$ PET/CT (58). Although not leading to an underestimation of disease, staging with whole-body MRI was found in one report to bear the risk of considerably overstaging lymphoma patients, with a consequent impact on therapeutic decisions (60). This more critical report outlines the need for more reliable data on the utility of MRI for whole-body staging of lymphoma patients. However, in lymphoma patients our first experiences with whole-body PET/MRI, which we currently acquire in addition to ${ }^{18} \mathrm{~F}-\mathrm{FDG} \mathrm{PET} / \mathrm{CT}$, indicate a good concordance with findings on PET/CT (Fig. 4).
Because of the lack of radiation exposure of MRI, compared with CT, PET/MRI may evolve as an alternative to $\mathrm{PET} / \mathrm{CT}$ in potentially curable patients.

Restaging and Response to Therapy. Data on restaging lymphoma patients and assessing their response to therapy are not available at present. Generally, the therapy regime initiated in lymphoma patients depends on the stage of the disease and then is adapted to the individual response and risk of progression (50). Different studies have assessed the option of monitoring therapy response early so as to adapt tumor treatment to therapy response (61). Although this approach is still considered experimental, all other patients will be restaged after completion of therapy. In recent years, ${ }^{18} \mathrm{~F}$-FDG PET and ${ }^{18} \mathrm{~F}$-FDG PET/CT have been included in the guidelines and are considered essential for therapy monitoring of diffuse large B-cell lymphoma and Hodgkin disease (51). Metaanalyses have demonstrated that ${ }^{18}$ F-FDG PET and ${ }^{18}$ F-FDG PET/CT are capable of assessing response early and have detected residual disease with up to a $90 \%$ sensitivity and $91 \%$ specificity in patients undergoing classic chemotherapy $(62,63)$. These imaging methods are predictive of progression-free survival, with negative ${ }^{18} \mathrm{~F}$-FDG PET findings indicating a higher probability of progression-free survival $(64,65)$. These promising results are hampered by the results of more recent prospective studies, which were undertaken to evaluate the predictive value of ${ }^{18} \mathrm{~F}$-FDG PET for early evaluation of therapy evaluation but found a rather low PPV for disease progression $(66,67) .{ }^{18} \mathrm{~F}-\mathrm{FDG}$ PET/CT findings after 2-3 cycles had a low PPV of $42 \%$ for progression or relapse of disease and a NPV of 77\% (67). This low PPV has been reported in studies evaluating therapy response to rituximab-based chemotherapy (rituximab, cyclophosphamide, hydroxydaunomycin, vincristine, and prednisone [R-CHOP]). The available literature indicates that false-positives are more frequently seen in rituximab-based therapy schemes than in classic chemotherapy (66). Moreover, for various reasons, false-positive as well as false-negative PET results
FIGURE 4. A 49-y-old patient with nonHodgkin lymphoma. Bone-windowed coronal CT (A) does not depict spread of paravertebral lymphoma masses (arrowhead) into twelfth thoracic and first lumbar vertebrae, which are visible on coronal ${ }^{18} \mathrm{~F}-\mathrm{FDG} \mathrm{PET} /$ CT (arrows) (B). Coronal short- $\tau$ inversion recovery MRI (C) and coronal ${ }^{18} \mathrm{~F}-\mathrm{FDG}$ PET/ MRI (D) better depict and confirm bone infiltration (arrows).
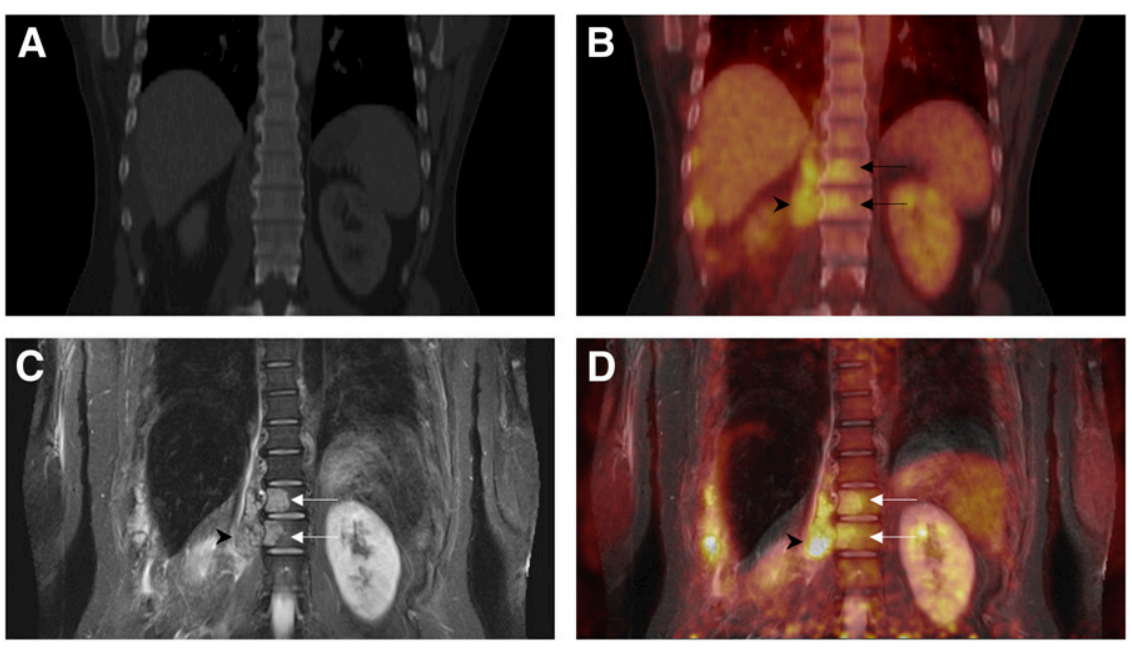
occur (68). However, the PPV and NPV of ${ }^{18}$ F-FDG PET/ $\mathrm{CT}$ for progression-free survival after completion of chemotherapy were $71 \%$ and $80 \%$, respectively, even for R-CHOP (67). With regard to these problems, MRI, especially diffusion-weighted imaging, might be of value in restaging of disease and evaluation of therapy response. MRI, by applying a combination of morphologic (size) and functional (adenylate cyclase measurements) parameters, has been shown to detect $100 \%$ of residual lymph node sites that were positive on ${ }^{18} \mathrm{~F}-\mathrm{FDG}$ PET/CT (reference standard) but resulted in 2 false-positive lesions in a comparative prospective pilot study that included 15 patients receiving chemotherapy (69). According to a subanalysis of the same study, the evaluation of morphologic MRI sequences led to a high number of false-positive lesions. The combination of size criteria with visual ADC analysis then reduced the number of false-positive findings to 2 lesions. Lymph nodes with residual disease, as well as false-positive lymph nodes, demonstrated a significant increase in adenylate cyclase compared with the baseline scan, indicating that the diagnosis on diffusionweighted MRI was correct (69). The use of PET/MRI instead of PET/CT in the surveillance of lymphoma patients undergoing chemotherapy may also be helpful for the differentiation of thymic rebound from recurrent lymphoma of the mediastinum. Chemical shift MRI provides MR images with 2 different contrasts (in-phase and opposed-phase images), depending on the fat-to-water ratio. This technique, by the detection of fat within a tissue mass, allows for the discrimination of hyperplastic thymic tissue from tumor tissue (70).

Although these potential advantages need to be confirmed by larger studies, functional PET/MRI comprising diffusion-weighted and chemical shift imaging represents a promising tool for response assessment in lymphoma patients.

\section{CONCLUSION}

Literature on integrated PET/MRI in oncologic applications is still limited. According to first experiences with this imaging technique and the available data on whole-body MRI and PET/CT, PET/MRI can be expected to be of benefit in T-staging of primary bone tumors and soft-tissue sarcomas. For N-staging, PET/MRI seems to provide similar accuracy to PET/CT. The diagnostic performance of the different imaging modalities for M-staging strongly depends on the location-that is, the organ harboring metastases. Therefore M-staging will benefit from MRI soft-tissue contrast and accuracy in the brain, the liver, and bone. The simultaneous acquisition of functional MRI and PET data promises to enhance assessments of tumor response to therapy. In general, PET/MRI will be indicated and perform superiorly to PET/CT in those oncologic indications that require high soft-tissue contrast for diagnosis. Indications in which soft-tissue contrast is of limited importance will probably remain the domain of the workhorse, PET/CT.

\section{REFERENCES}

1. Edge SB, Byrd DR, Compton CC, et al., eds. AJCC Cancer Staging Handbook: From the AJCC Cancer Staging Manual. 7th ed. New York, NY: Springer; 2009.

2. Hofmann M, Pichler B, Schölkopf B, Beyer T. Towards quantitative PET/MRI: a review of MR-based attenuation correction techniques. Eur J Nucl Med Mol Imaging. 2009;36(suppl 1):S93-S104.

3. Hogendoorn PC, Athanasou N, Bielack S, et al. Bone sarcomas: ESMO Clinical Practice Guidelines for diagnosis, treatment and follow-up. Ann Oncol. 2010;21 (suppl 5):204-213.

4. Zhang J, Cheng K, Ding Y, Liang W, Vanel D, Cheng X. Study of single voxel ${ }^{1} \mathrm{H}$ MR spectroscopy of bone tumors: differentiation of benign from malignant tumors. Eur J Radiol. December 12, 2011 [Epub ahead of print].

5. Tateishi U, Yamaguchi U, Seki K, Terauchi T, Arai Y, Kim EE. Bone and softtissue sarcoma: preoperative staging with fluorine 18 fluorodeoxyglucose PET/ CT and conventional imaging. Radiology. 2007;245:839-847.

6. Gerth HU, Juergens KU, Dirksen U, Gerss J, Schober O, Franzius C. Significant benefit of multimodal imaging: PET/CT compared with PET alone in staging and follow-up of patients with Ewing tumors. J Nucl Med. 2007;48:1932-1939.

7. Denecke T, Hundsdörfer P, Misch D, et al. Assessment of histological response of paediatric bone sarcomas using FDG PET in comparison to morphological volume measurement and standardized MRI parameters. Eur J Nucl Med Mol Imaging. 2010;37:1842-1853.

8. Uhl M, Saueressig U, van Buiren M, et al. Osteosarcoma: preliminary results of in vivo assessment of tumor necrosis after chemotherapy with diffusion- and perfusion-weighted magnetic resonance imaging. Invest Radiol. 2006;41:618-623.

9. Smith HS. Painful osseous metastases. Pain Physician. 2011;14:E373-E403.

10. Yang HL, Liu T, Wang XM, Xu Y, Deng SM. Diagnosis of bone metastases: a meta-analysis comparing ${ }^{18} \mathrm{FDG}$ PET, CT, MRI and bone scintigraphy. Eur Radiol. 2011;21:2604-2617.

11. Schmidt GP, Schoenberg SO, Schmid R, et al. Screening for bone metastases: whole-body MRI using a 32-channel system versus dual-modality PET-CT. Eur Radiol. 2007;17:939-949.

12. Qu X, Huang X, Yan W, Wu L, Dai K. A meta-analysis of ${ }^{18}$ FDG-PET-CT, ${ }^{18}$ FDG-PET, MRI and bone scintigraphy for diagnosis of bone metastases in patients with lung cancer. Eur J Radiol. 2012;81:1007-1015.

13. Liu T, Cheng T, Xu W, Yan WL, Liu J, Yang HL. A meta-analysis of ${ }^{18}$ FDGPET, MRI and bone scintigraphy for diagnosis of bone metastases in patients with breast cancer. Skeletal Radiol. 2011;40:523-531.

14. Heusner T, Gölitz P, Hamami M, et al. "One-stop-shop" staging: should we prefer FDG-PET/CT or MRI for the detection of bone metastases? Eur J Radiol. 2011;78:430-435.

15. Imamura F, Kuriyama K, Seto T, et al. Detection of bone marrow metastases of small cell lung cancer with magnetic resonance imaging: early diagnosis before destruction of osseous structure and implications for staging. Lung Cancer. 2000;27:189-197.

16. Reischauer C, Froehlich JM, Koh DM, et al. Bone metastases from prostate cancer: assessing treatment response by using diffusion-weighted imaging and functional diffusion maps-initial observations. Radiology. 2010;257:523-531.

17. Casali PG, Blay JY. Soft tissue sarcomas: ESMO Clinical Practice Guidelines for diagnosis, treatment and follow-up. Ann Oncol. 2010;21(suppl 5):198-203.

18. Berquist TH, Ehman RL, King BF, Hodgman CG, Ilstrup DM. Value of MR imaging in differentiating benign from malignant soft-tissue masses: study of 95 lesions. AJR. 1990;155:1251-1255.

19. Kransdorf MJ, Murphey MD. Radiologic evaluation of soft-tissue masses: a current perspective. AJR. 2000;175:575-587.

20. Doganay S, Altinok T, Alkan A, Kahraman B, Karakas HM. The role of MRS in the differentiation of benign and malignant soft tissue and bone tumors. Eur $J$ Radiol. 2011;79:e33-e37.

21. Ricard F, Cimarelli S, Deshayes E, Mognetti T, Thiesse P, Giammarile F. Additional benefit of F-18 FDG PET/CT in the staging and follow-up of pediatric rhabdomyosarcoma. Clin Nucl Med. 2011;36:672-677.

22. Sinha S, Peach AH. Diagnosis and management of soft tissue sarcoma. BMJ. 2010;341:c7170.

23. Tateishi U, Hosono A, Makimoto A, et al. Comparative study of FDG PET/CT and conventional imaging in the staging of rhabdomyosarcoma. Ann Nucl Med. 2009;23:155-161.

24. Baum SH, Frühwald M, Rahbar K, Wessling J, Schober O, Weckesser M. Contribution of PET/CT to prediction of outcome in children and young adults with rhabdomyosarcoma. J Nucl Med. 2011;52:1535-1540.

25. Yokouchi M, Terahara M, Nagano S, et al. Clinical implications of determination of safe surgical margins by using a combination of CT and ${ }^{18}$ FDG-positron emission tomography in soft tissue sarcoma. BMC Musculoskelet Disord. 2011; $12: 166$. 
26. Völker T, Denecke T, Steffen I, et al. Positron emission tomography for staging of pediatric sarcoma patients: results of a prospective multicenter trial. J Clin Oncol. 2007;25:5435-5441.

27. Tateishi U, Yamaguchi U, Maeda T, et al. Staging performance of carbon-11 choline positron emission tomography/computed tomography in patients with bone and soft tissue sarcoma: comparison with conventional imaging. Cancer Sci. 2006;97:1125-1128.

28. Piperkova E, Mikhaeil M, Mousavi A, et al. Impact of PET and CT in PET/CT studies for staging and evaluating treatment response in bone and soft tissue sarcomas. Clin Nucl Med. 2009;34:146-150.

29. Stacchiotti S, Collini P, Messina A, et al. High-grade soft-tissue sarcomas: tumor response assessment-pilot study to assess the correlation between radiologic and pathologic response by using RECIST and Choi criteria. Radiology. 2009; 251:447-456.

30. Wang X, Jacobs MA, Fayad L. Therapeutic response in musculoskeletal soft tissue sarcomas: evaluation by MRI. NMR Biomed. 2011;24:750-763.

31. Schnapauff D, Zeile M, Niederhagen MB, et al. Diffusion-weighted echo-planar magnetic resonance imaging for the assessment of tumor cellularity in patients with soft-tissue sarcomas. J Magn Reson Imaging. 2009;29:1355-1359.

32. Dudeck O, Zeile M, Pink D, et al. Diffusion-weighted magnetic resonance imaging allows monitoring of anticancer treatment effects in patients with softtissue sarcomas. J Magn Reson Imaging. 2008;27:1109-1113.

33. Evilevitch V, Weber WA, Tap WD, et al. Reduction of glucose metabolic activity is more accurate than change in size at predicting histopathologic response to neoadjuvant therapy in high-grade soft-tissue sarcomas. Clin Cancer Res. 2008;14:715-720.

34. Benz MR, Czernin J, Allen-Auerbach MS, et al. FDG-PET/CT imaging predicts histopathologic treatment responses after the initial cycle of neoadjuvant chemotherapy in high-grade soft-tissue sarcomas. Clin Cancer Res. 2009;15:28562863.

35. Benz MR, Czernin J, Allen-Auerbach MS, et al. $3^{\prime}$-deoxy- $3^{\prime}-\left[{ }^{18}\right.$ F]fluorothymidine positron emission tomography for response assessment in soft tissue sarcoma: a pilot study to correlate imaging findings with tissue thymidine kinase 1 and Ki-67 activity and histopathologic response. Cancer. 2012;118:3135-3144.

36. Gershenwald JE, Soong SJ, Balch CM, et al. 2010 TNM staging system for cutaneous melanoma. . .and beyond. Ann Surg Oncol. 2010;17:1475-1477.

37. Dummer R, Hauschild A, Guggenheim M, et al. Melanoma: ESMO clinical practice guidelines for diagnosis, treatment and follow-up. Ann Oncol. 2010; 21(suppl 5):v194-v197.

38. Xing Y, Bronstein Y, Ross MI, et al. Contemporary diagnostic imaging modalities for the staging and surveillance of melanoma patients: a meta-analysis. $J$ Natl Cancer Inst. 2011;103:129-142.

39. Wagner JD, Schauwecker D, Davidson D, et al. Prospective study of fluorodeoxyglucose-positron emission tomography imaging of lymph node basins in melanoma patients undergoing sentinel node biopsy. J Clin Oncol. 1999;17: 1508-1515.

40. Wagner JD, Davidson D, Coleman JJ, et al. Lymph node tumor volumes in patients undergoing sentinel lymph node biopsy for cutaneous melanoma. Ann Surg Oncol. 1999;6:398-404.

41. Horn J, Lock-Andersen J, Sjøstrand H, Loft A. Routine use of FDG-PET scans in melanoma patients with positive sentinel node biopsy. Eur J Nucl Med Mol Imaging. 2006;33:887-892.

42. Müller-Horvat C, Radny P, Eigentler TK, et al. Prospective comparison of the impact on treatment decisions of whole-body magnetic resonance imaging and computed tomography in patients with metastatic malignant melanoma. Eur $J$ Cancer. 2006;42:342-350.

43. Pfannenberg C, Aschoff P, Schanz S, et al. Prospective comparison of ${ }^{18} \mathrm{~F}$-fluorodeoxyglucose positron emission tomography/computed tomography and whole-body magnetic resonance imaging in staging of advanced malignant melanoma. Eur J Cancer. 2007;43:557-564.

44. Laurent V, Trausch G, Bruot O, Olivier P, Felblinger J, Régent D. Comparative study of two whole-body imaging techniques in the case of melanoma metastases: advantages of multi-contrast MRI examination including a diffusionweighted sequence in comparison with PET-CT. Eur J Radiol. 2010;75:376-383.

45. Essler M, Link A, Belloni B, et al. Prognostic value of $\left[{ }^{18} \mathrm{~F}\right]$-fluoro-deoxy-glucose PET/CT, S100 or MIA for assessment of cancer-associated mortality in patients with high risk melanoma. PLoS ONE. 2011;6:324632.

46. Peric B, Zagar I, Novakovic S, Zgajnar J, Hocevar M. Role of serum S100B and PET-CT in follow-up of patients with cutaneous melanoma. BMC Cancer. 2011;11:328.

47. Gulec SA, Faries MB, Lee CC, et al. The role of fluorine-18 deoxyglucose positron emission tomography in the management of patients with metastatic melanoma: impact on surgical decision making. Clin Nucl Med. 2003;28:961965.
48. Strobel K, Dummer R, Steinert HC, et al. Chemotherapy response assessment in stage IV melanoma patients: comparison of ${ }^{18} \mathrm{~F}$-FDG-PET/CT, CT, brain MRI, and tumor marker S-100B. Eur J Nucl Med Mol Imaging. 2008;35:1786-1795.

49. Olsen DR, Singstad TE, Rofstad EK. Effects of hyperthermia on bioenergetic status and phosphorus T1S in human melanoma xenografts monitored by ${ }^{31} \mathrm{P}-$ MRS. Magn Reson Imaging. 1999;17:1049-1056.

50. Hutchings M, Barrington SF. PET/CT for therapy response assessment in lymphoma. J Nucl Med. 2009;50(suppl 1):S21-S30.

51. Cheson BD, Pfistner B, Juweid ME, et al. Revised response criteria for malignant lymphoma. J Clin Oncol. 2007;25:579-586.

52. Juweid ME, Stroobants S, Hoekstra OS, et al. Use of positron emission tomography for response assessment of lymphoma: consensus of the Imaging Subcommittee of International Harmonization Project in Lymphoma. J Clin Oncol. 2007;25:571-578.

53. Tilly H, Dreyling M, Group EGW. Diffuse large B-cell non-Hodgkin's lymphoma: ESMO Clinical Practice Guidelines for diagnosis, treatment and follow-up. Ann Oncol. 2010;21(suppl 5):v172-v174.

54. Pelosi E, Pregno P, Penna D, et al. Role of whole-body $\left[{ }^{18} \mathrm{~F}\right]$ fluorodeoxyglucose positron emission tomography/computed tomography (FDG-PET/CT) and conventional techniques in the staging of patients with Hodgkin and aggressive non Hodgkin lymphoma. Radiol Med (Torino). 2008;113:578-590.

55. Wu LM, Chen FY, Jiang XX, Gu HY, Yin Y, Xu JR. ${ }^{18}$ F-FDG PET, combined FDG-PET/CT and MRI for evaluation of bone marrow infiltration in staging of lymphoma: a systematic review and meta-analysis. Eur J Radiol. 2012;81:303-311.

56. Kwee TC, van Ufford HM, Beek FJ, et al. Whole-body MRI, including diffusionweighted imaging, for the initial staging of malignant lymphoma: comparison to computed tomography. Invest Radiol. 2009;44:683-690.

57. Punwani S, Taylor SA, Bainbridge A, et al. Pediatric and adolescent lymphoma: comparison of whole-body STIR half-Fourier RARE MR imaging with an enhanced PET/CT reference for initial staging. Radiology. 2010;255:182-190.

58. Lin C, Luciani A, Itti E, et al. Whole-body diffusion-weighted magnetic resonance imaging with apparent diffusion coefficient mapping for staging patients with diffuse large B-cell lymphoma. Eur Radiol. 2010;20:2027-2038.

59. Abdulqadhr G, Molin D, Aström G, et al. Whole-body diffusion-weighted imaging compared with FDG-PET/CT in staging of lymphoma patients. Acta Radiol. 2011;52:173-180.

60. van Ufford HM, Kwee TC, Beek FJ, et al. Newly diagnosed lymphoma: initial results with whole-body T1-weighted, STIR, and diffusion-weighted MRI compared with ${ }^{18}$ F-FDG PET/CT. AJR. 2011;196:662-669.

61. Jochelson M, Mauch P, Balikian J, Rosenthal D, Canellos G. The significance of the residual mediastinal mass in treated Hodgkin's disease. J Clin Oncol. 1985; 3:637-640.

62. Zijlstra JM, Lindauer-van der Werf G, Hoekstra OS, Hooft L, Riphagen II, Huijgens PC. ${ }^{18} \mathrm{~F}$-fluoro-deoxyglucose positron emission tomography for posttreatment evaluation of malignant lymphoma: a systematic review. Haematologica. 2006;91:522-529.

63. Isasi CR, Lu P, Blaufox MD. A metaanalysis of ${ }^{18} \mathrm{~F}$-2-deoxy-2-fluoro-D-glucose positron emission tomography in the staging and restaging of patients with lymphoma. Cancer. 2005;104:1066-1074.

64. Terasawa T, Lau J, Bardet S, et al. Fluorine-18-fluorodeoxyglucose positron emission tomography for interim response assessment of advanced-stage Hodgkin's lymphoma and diffuse large B-cell lymphoma: a systematic review. J Clin Oncol. 2009;27:1906-1914.

65. Juweid ME, Wiseman GA, Vose JM, et al. Response assessment of aggressive non-Hodgkin's lymphoma by integrated International Workshop Criteria and fluorine-18-fluorodeoxyglucose positron emission tomography. J Clin Oncol. 2005;23:4652-4661.

66. Pregno P, Chiappella A, Bellò M, et al. Interim 18-FDG-PET/CT failed to predict the outcome in diffuse large B-cell lymphoma patients treated at the diagnosis with rituximab-CHOP. Blood. 2012;119:2066-2073.

67. Cashen AF, Dehdashti F, Luo J, Homb A, Siegel BA, Bartlett NL. ${ }^{18}$ F-FDG PET/ CT for early response assessment in diffuse large B-cell lymphoma: poor predictive value of international harmonization project interpretation. $\mathrm{J} \mathrm{Nucl} \mathrm{Med}$. 2011;52:386-392.

68. Castellucci P, Nanni C, Farsad M, et al. Potential pitfalls of ${ }^{18}$ F-FDG PET in a large series of patients treated for malignant lymphoma: prevalence and scan interpretation. Nucl Med Commun. 2005;26:689-694.

69. Lin C, Itti E, Luciani A, et al. Whole-body diffusion-weighted imaging with apparent diffusion coefficient mapping for treatment response assessment in patients with diffuse large B-cell lymphoma: pilot study. Invest Radiol. 2011; 46:341-349.

70. Inaoka T, Takahashi K, Mineta M, et al. Thymic hyperplasia and thymus gland tumors: differentiation with chemical shift MR imaging. Radiology. 2007;243: 869-876. 